\title{
The effects of taxanes, vorinostat and doxorubicin on growth and proliferation of Echinococcus multilocularis metacestodes assessed with magnetic resonance imaging and simultaneous positron emission tomography
}

\author{
Xiangsheng Huang ${ }^{1, *}$, Stefan Wiehr ${ }^{2, *}$, Anna-Maria Wild ${ }^{2}$, Patrick Voßberg ${ }^{1}$, \\ Wolfgang Hoffmann ${ }^{1}$, Beate Grüner ${ }^{3}$, Carsten Köhler ${ }^{1}$ and Peter T. Soboslay ${ }^{1}$ \\ ${ }^{1}$ Institute for Tropical Medicine, Eberhard Karls University, Tübingen, Germany \\ ${ }^{2}$ Werner Siemens Imaging Center, Department of Preclinical Imaging and Radiopharmacy, Eberhard Karls University, \\ Tübingen, Germany \\ ${ }^{3}$ Section of Clinical Immunology and Infectiology, University Clinics Ulm, UIm, Germany \\ *These authors contributed equally to this work \\ Correspondence to: Peter T. Soboslay, email: peter.soboslay@uni-tuebingen.de \\ Keywords: echinococcus multilocularis, metacestode; taxanes, paclitaxel, docetaxel, histone deacetylase inhibitor, vorinostat, \\ doxorubicin; drug exposure; positron emission tomography; magnetic resonance imaging \\ Received: August 09, $2017 \quad$ Accepted: January 02, $2018 \quad$ Published: January 10, 2018 \\ Copyright: Huang et al. This is an open-access article distributed under the terms of the Creative Commons Attribution License 3.0 \\ (CC BY 3.0), which permits unrestricted use, distribution, and reproduction in any medium, provided the original author and source \\ are credited.
}

\section{ABSTRACT}

Cytostatic drugs used in cancer therapy were evaluated for their capacity to inhibit Echinococcus multilocularis metacestode growth and proliferation. Metacestode tissues were exposed in vitro to docetaxel, doxorubicin, navelbine, paclitaxel, and vorinostat for 1 week, then incubated in drug-free culture, and thereafter metacestodes were injected into the peritoneum of Meriones unguiculatus. Magnetic resonance imaging (MRI) and simultaneous positron emission tomography (PET) were applied to monitor in vivo growth of drug-exposed $E$. multilocularis in Meriones. At 3 month p.i., docetaxel (at $10 \mu \mathrm{M}, 5 \mu \mathrm{M}$ and $2 \mu \mathrm{M}$ ) inhibited in vivo growth and proliferation of $E$. multilocularis, and at 5 months p.i., only in the $2 \mu \mathrm{M}$ docetaxel exposure group $0.3 \mathrm{~cm}^{3}$ of parasite tissue was found. With paclitaxel and navelbine the in vivo growth of metacestodes was suppressed until 3 months p.i., thereafter, parasite tissues enlarged up to $3 \mathrm{~cm}^{3}$ in both groups. $E$. multilocularis tissues of more than $\mathbf{1 0} \mathbf{g}$ developed in Meriones injected with metacestodes which were previously exposed in vitro to doxorubicin, navelbine, paclitaxel or vorinostat. In Meriones infected with metacestodes previously exposed to docetaxel, the in vivo grown parasite tissues weighted $0.2 \mathrm{~g}$. In vitro cultured $E$. multilocularis metacestodes exposed to docetaxel did not produce vesicles until 7 weeks post drug exposure, while metacestodes exposed to doxorubicin, navelbine and vorinostat proliferated continuously. In summary, docetaxel, and less efficaciously paclitaxel, inhibited in vivo and in vitro parasite growth and proliferation, and these observations suggest further experimental studies with selected drug combinations which may translate into new treatment options against alveolar echinococcosis.

\section{INTRODUCTION}

Alveolar echinococcosis (AE), a life-threatening zoonosis for humans, is caused by the proliferative growth of the larval metacestode of Echinococcus multilocularis (Em) within tissues and organs, mostly the liver [1]. Surgical removal of the infested organs or tissues and long-lasting benzimidazole (BMZ) therapy 
will improve the survival rate of patients, however, the chemotherapeutic options remain limited and new treatments of AE are needed. Long-lasting BMZ treatment is parasitostatic and not parasitocidal, and as such, despite surgical resection of parasite tissues, undetected and residual larval metacestodes may restart growth with progression of disease as soon as chemotherapy is stopped.

E. multilocularis can be maintained in an experimental life cycle by intra-peritoneal inoculation of larval metacestodes into permissive hosts such as Meriones unguiculatus (gerbils). The metacestode larvae will progressively grow in gerbils and parasite tissues can be collected and used for research and diagnostic purposes. To evaluate the efficacy of chemotherapy, E. multilocularis infected gerbils can be treated with parasiticides or cytostatic drugs [2-4]. In vitro cultured metacestodes can selectively be exposed to anti-helminthic drugs or new compounds to evaluate their parasitocidal or parasitostatic efficacy [5-9], or else, after intra-peritoneal transfer of these drug-exposed metacestodes into permissive recipients, e.g. gerbils, the viability and proliferative capacity of the parasite tissues can be evaluated in vivo [10-12]. Cytostatic drugs used in cancer therapy were applied to determine their potential to inhibit E. multilocularis metacestode growth and proliferation $[2-4,7,9,11,12]$. The selection of cytostatic drugs was based on gene expression analysis of the E. multilocularis metacestode tissue, which disclosed that metacestodes expressed genes associated with proliferation of cancer cells and progressive tumor growth, which can be inhibited by specific anti-cancer compounds [11]. Inhibitors of tubulin genes were chosen for this study. The taxanes (docetaxel, paclitaxel) and vinorelbine (navelbine) are microtubule-stabilizing agents that function primarily by interfering with spindle microtubule dynamics causing cell cycle arrest and apoptosis [13]. Paclitaxel at clinically achievable concentrations inhibited in vitro the survival of larval cells, protoscoleces and metacestodes of Echinococcus granulosus [9], while metacestode vesicles of $E$. multilocularis when in vitro cultured and exposed to paclitaxel, docetaxel or vorinostat were not affected [12]. Navelbine has been tested in vivo against E. multilocularis by Hübner et al. 2010, and in vitro by Stadelmann et al. 2014, and the drug did not did not show parasitocidal or clear parasitostatic effects $[11,12]$. Vorinostat (SAHA) is one of the most potent inhibitors of histone acetyltransferases and histone deacetylases (HDAC) and clinical trials have shown it to be effective against cutaneous T-cell lymphoma and other malignancies [14]. The anti-cancer agent doxorubicin is a membrane permeable drug which mediates DNA damage and inhibits DNA synthesis, promotes reactive oxygen species and cell senescence, it will cause cardiotoxicity and drug resistance while being of low bio-availability [15]. With doxorubicin, when bound to bio-degradable nanoparticles and applied into E. multilocularis infected mice, the hepatic parasite development and metacestode viability were reduced, but free doxorubicin had no anti-parasitic activity [4]. For the pre-clinical evaluations of therapeutic effects of tumor suppressors in various types of cancers, in vivo positron emission tomography (PET) combined with ex vivo histology and nuclear magnetic resonance (NMR) metabolic fingerprinting was successfully applied for therapy monitoring $[16,17]$. Such in vivo imaging techniques have also been used for non-invasive diagnosis of invasive pulmonary aspergillosis [18]. The follow-up of patients with AE was accomplished with delayed glucose traced-assisted PET which facilitated the differentiation between active and inactive liver lesions [19]. In experimental animal models of $\mathrm{AE}$ magnetic resonance imaging [20] or ultrasound [21] were successfully applied to follow-up parasite growth in living animals during the treatment phase.

In this study, cytostatic drugs at present used in cancer therapy were evaluated for their capacity to inhibit E. multilocularis metacestode growth and proliferation. We have exposed in vitro parasite tissues to drug concentrations used for the therapy of cancer patients, this was to evaluate the parasitostatic or parasitocidal efficacy of these cytostatic drugs at concentrations not applicable and adapted for in vivo use with experimental animals. After the in vitro exposure, and one week of culture in drug-free medium to wash out residual drug from the parasite tissue blocks, the E. multilocularis metacestode tissues were injected into parasite-susceptible animals (Meriones unguiculatus, gerbils) and this approach evaluated whether the preceding drug-exposure would inhibit in vivo parasite growth or has had a parasitocidal effect. Magnetic resonance imaging (MRI) and simultaneous positron emission tomography (PET) with the 2-deoxy-2-[ $\left.{ }^{18} \mathrm{~F}\right]$-fluoro-D-glucose ([ $\left.\left.{ }^{18} \mathrm{~F}\right] \mathrm{FDG}\right)$ tracer were applied [20] to monitor in vivo the growth of drugexposed E. multilocularis metacestodes, and in parallel, drug-exposed parasite tissues were studied in vitro for growth and proliferative "budding" of metacestode vesicles.

\section{RESULTS}

\section{Selection of cytostatic drugs for in vitro exposure with $E$. multilocularis metacestodes}

The analysis of E. multilocularis cDNA hybridization to human microarrays showed strongly expressed cancerrelated genes in metacestodes. The signal strength of hybridization of $E$. multilocularis cDNA to human genes was prominent for member of the RAS oncogene family (RAB2), the folate receptor (FOLR1), the eukaryotic translation elongation factor 1 alpha 1 (EEF1A1), tubulins (TUBA1A, TUBA1C, TUBB3), aquaporin, calreticulin, and synuclein alpha (Table 1 PartA, Supplementary Table 1 PartB). These microarray results suggested similarities between E. multilocularis metacestode proliferation and 
Table 1A: The signal strength of hybridization of Echinococcus multilocularis cDNA to human microarray chip

\begin{tabular}{|c|c|c|c|c|}
\hline $\begin{array}{l}\text { Genbank } \\
\text { Accession No. }\end{array}$ & $\begin{array}{c}\text { Signal } \\
\text { Strength } \\
\text { Sample } 1\end{array}$ & $\begin{array}{c}\text { Signal } \\
\text { Strength } \\
\text { Sample } 2 \\
\end{array}$ & $\begin{array}{l}\text { Mean Signal } \\
\text { Strength } \\
(\mathrm{S} 1+\mathbf{S} 2)\end{array}$ & Gene Title \\
\hline AA535244 & 1.050 & 837,5 & 944 & RAB2, member RAS oncogene family \\
\hline AL515273 & 499,6 & 433,1 & 466 & eukaryotic translation elongation factor 1 alpha 1 \\
\hline AK098740 & 440,4 & 468,6 & 455 & hypothetical protein LOC202051 \\
\hline BE221212 & 631,5 & 140,3 & 386 & collagen, type I, alpha 1 \\
\hline L36675 & 414,8 & 305,7 & 360 & $\begin{array}{c}\text { synuclein, alpha (non A4 component of amyloid } \\
\text { precursor) }\end{array}$ \\
\hline AJ006206 & 366,8 & 308,6 & 338 & B1 for mucin /// similar to MUC-B1 \\
\hline AL581768 & 399,7 & 244,6 & 322 & tubulin, alpha, ubiquitous \\
\hline AF000381 & 376 & 229,3 & 303 & folate receptor 1 (adult) \\
\hline AW015506 & 284,9 & 298,9 & 292 & aquaporin 2 (collecting duct) \\
\hline NM_001402 & 294,3 & 237,2 & 266 & eukaryotic translation elongation factor 1 alpha 1 \\
\hline BE964125 & 322,6 & 207,2 & 265 & $\begin{array}{l}\text { similar to eukaryotic translation elongation factor } 1 \text { alpha } \\
\text { 1; eukaryotic translation elongation factor } 1 \text { alpha } 1 \text {-like } \\
\text { 14; CTCL tumor antigen; translation elongation factor } 1 \\
\text { alpha 1-like 14; prostate tumor-inducing protein 1; EF1a- } \\
\text { like protein; }\end{array}$ \\
\hline AL137719 & 257,8 & 248,2 & 253 & $\begin{array}{c}\text { olfactory receptor, family 7, subfamily E, member } 104 \\
\text { pseudogene }\end{array}$ \\
\hline BE786672 & 299,2 & 203,3 & 251 & eukaryotic translation elongation factor 1 alpha 1 \\
\hline AK098354 & 292,7 & 208,7 & 251 & BS 3076 \\
\hline AI378706 & 214,6 & 204,5 & 210 & Calreticulin \\
\hline AW001777 & 235,1 & 176 & 206 & hypothetical LOC400843 \\
\hline U15197 & 283 & 127,6 & 205 & $\begin{array}{l}\text { ABO blood group (transferase A, alpha 1-3-N-ace } \\
\text { tylgalactosaminyltransferase; transferase B, alpha } \\
\text { 1-3-galactosyltransferase) }\end{array}$ \\
\hline AW271225 & 220,4 & 163,1 & 192 & oxysterol binding protein-like 5 \\
\hline BI912454 & 233,1 & 119,5 & 176 & hypothetical locus LOC338799 \\
\hline AK096064 & 210 & 141,1 & 176 & --- \\
\hline NM_024732 & 194,1 & 154,1 & 174 & hypothetical protein FLJ14351 \\
\hline NM_152909 & 208,1 & 129,4 & 169 & zinc finger protein 548 \\
\hline AW612342 & 196,9 & 127,3 & 162 & Rho-associated, coiled-coil containing protein kinase 1 \\
\hline AK093104 & 179,3 & 123 & 151 & hypothetical protein FLJ35785 \\
\hline AL133228 & 198,3 & 100,8 & 150 & thymosin, beta $4, \mathrm{X}$-linked /// thymosin-like 3 \\
\hline AI820801 & 203,9 & 82,7 & 143 & Transcribed locus \\
\hline Z22814 & 155,6 & 124,7 & 140 & atrophin 1 \\
\hline NM_153606 & 182,4 & 86,8 & 135 & family with sequence similarity 71 , member A \\
\hline BF223582 & 180,9 & 87,9 & 134 & --- \\
\hline AV710357 & 196 & 70,9 & 133 & --- \\
\hline AA 046650 & 172,7 & 89 & 131 & TRIO and F-actin binding protein \\
\hline ВC005946 & 185,9 & 75,2 & 131 & tubulin alpha 6 /// tubulin alpha 6 \\
\hline NM_001403 & 81,4 & 172 & 127 & eukaryotic translation elongation factor 1 alpha 1 \\
\hline NM_014030 & 127,9 & 122 & 125 & G protein-coupled receptor kinase interactor 1 \\
\hline
\end{tabular}




\begin{tabular}{|c|c|c|c|c|}
\hline ВC004949 & 141,2 & 107,3 & 124 & tubulin alpha 6 \\
\hline AI869532 & 113,6 & 131,1 & 122 & Nuclear factor related to kappaB binding protein \\
\hline W07773 & 109,2 & 129,4 & 119 & chromosome 19 open reading frame 22 \\
\hline BU928170 & 139,2 & 98,4 & 119 & Similar to F4N2.10 \\
\hline NM_001030 & 151,2 & 85,1 & 118 & ribosomal protein S27 (metallopanstimulin 1) \\
\hline BC013641 & 124,5 & 107,3 & 116 & Homo sapiens, clone IMAGE:4151631, mRNA \\
\hline Y15916 & 110,9 & 112,5 & 112 & collagen, type I, alpha 1 \\
\hline AJ 251708 & 177,6 & 45,1 & 111 & putative microtubule-binding protein \\
\hline U58856 & 108,5 & 114 & 111 & mannose receptor, $\mathrm{C}$ type 2 \\
\hline AW015517 & 95,3 & 126,6 & 111 & Follistatin-like 3 (secreted glycoprotein) \\
\hline AL565749 & 125,1 & 94,71 & 110 & tubulin, beta 3 \\
\hline AB009010 & 147,3 & 72,4 & 110 & ubiquitin $\mathrm{C}$ \\
\hline AJ296370 & 168,8 & 50 & 109 & --- \\
\hline BC015443 & 99,21 & 119,1 & 109 & Pseudogene similar to LOC112869 gene \\
\hline BE300252 & 140,7 & 77,2 & 109 & tubulin, alpha, ubiquitous \\
\hline AL031186 & 126,6 & 89,59 & 108 & EMI domain containing 1 \\
\hline BF246436 & 133,1 & 78,3 & 106 & eukaryotic translation initiation factor 1 \\
\hline AF343666 & 112,8 & 97,7 & 105 & $\begin{array}{c}\text { Translocation associated fusion protein IRTA1/IGA1 } \\
\text { (IRTA1/IGHA1) /// Translocation associated fusion } \\
\text { protein IRTA1/IGA1 (IRTA1/IGHA1) }\end{array}$ \\
\hline BC004952 & 129,4 & 75,3 & 102 & polycomb group ring finger 1 \\
\hline AW974499 & 99,1 & 103,4 & 101 & Rho GTPase activating protein 30 \\
\hline AI885873 & 122,4 & 78 & 100 & transportin 2 (importin 3 , karyopherin beta $2 b$ ) \\
\hline BE552347 & 108,6 & 91,8 & 100 & Kv channel interacting protein 2 \\
\hline BE813017 & 120,3 & 79,3 & 100 & --- \\
\hline
\end{tabular}

cancer progression and tissue metastases, and thus, the selection of drugs for the evaluation of their capacity to inhibit E. multilocularis growth and proliferation, was on FDA-approved compounds that disrupt normal function of microtubules and interfere with the cell division or replication. The taxanes docetaxel, paclitaxel and navelbine and also the histone deacetylase inhibitor SAHA (vorinostat) as well as doxorubicin were investigated in this study. E. multilocularis metacestodes were exposed in vitro to cytostatic drugs, then those drug-exposed parasite tissues were injected into Meriones unguiculatus (gerbils), and parasite growth and proliferation studied by MRI and PET.

\section{In vivo growth of drug-exposed $E$. multilocularis in Meriones unguiculatus}

In vivo volumetric MRI measurements were performed at two time points after inoculation of drugexposed E. multilocularis metacestode tissues into Meriones. Analysis of the MR images showed low or no parasite growth in infected Meriones if metacestodes were exposed to docetaxel in vitro, independent of the applied concentration (Figure 1A and 1F). At 3 month post transfer of drug-exposed metacestodes in Meriones, the MRI measurement detected $0 \mathrm{~mm}^{3}(n=2), 0$ and $4934 \mathrm{~mm}^{3}(n=2)$ and 0 and $6 \mathrm{~mm}^{3}(n=2)$ of parasite tissues in the docetaxel $10 \mu \mathrm{M}, 5 \mu \mathrm{M}$ and $2 \mu \mathrm{M}$ exposure groups, respectively. At 5 months p.i., the MRI measurement did not detect any metacestodes in the docetaxel $10 \mu \mathrm{M} 5 \mu \mathrm{M}$ and $2 \mu \mathrm{M}$ exposure groups.

The in vitro exposure of metacestode tissues to paclitaxel did not prevent their growth after transfer into the peritoneum of Meriones (Figure 1B and 1F). At 3 months p.i., metacestodes which were in vitro exposed to paclitaxel at concentrations of $10 \mu \mathrm{M}, 5 \mu \mathrm{M}$ and $2 \mu \mathrm{M}$ developed in Meriones into parasite tissues with volumes 1694 and $3316 \mathrm{~mm}^{3}(n=2) ; 973$ and $619 \mathrm{~mm}^{3}(n=2)$ and 6932 and $577 \mathrm{~mm}^{3}(n=2)$, respectively. At 5 months p.i. the MRI measurement determined $16370 \mathrm{~mm}^{3}(n=1)$, 1692 and $10931 \mathrm{~mm}^{3}(n=2)$ and 1933 and $18977 \mathrm{~mm}^{3}$ $(n=2)$ of parasite tissues in the paclitaxel $10 \mu \mathrm{M}$, $5 \mu \mathrm{gM}$ and $2 \mu \mathrm{M}$ exposure groups, respectively. Following navelbine exposure, small metacestode tissue volumes were detected at 2 months post transfer in Meriones, but parasite volumes enlarged at 5 months post transfer (Figure 1D and 1F).

When exposed to navelbine at concentrations of $4.5 \mathrm{ng} / \mathrm{ml}, 3 \mathrm{ng} / \mathrm{ml} 1.5 \mathrm{ng} / \mathrm{ml}$ and $0.75 \mathrm{ng} / \mathrm{ml}$, the tissue 
A

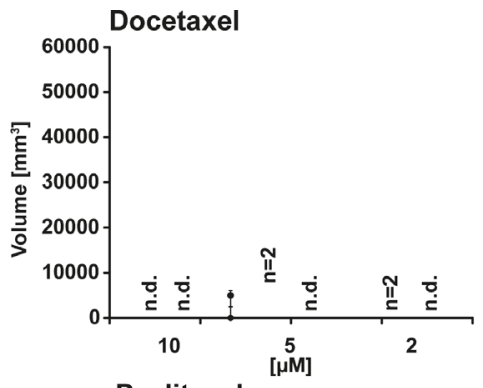

B

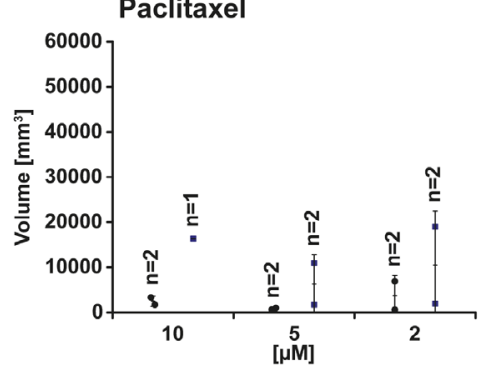

D

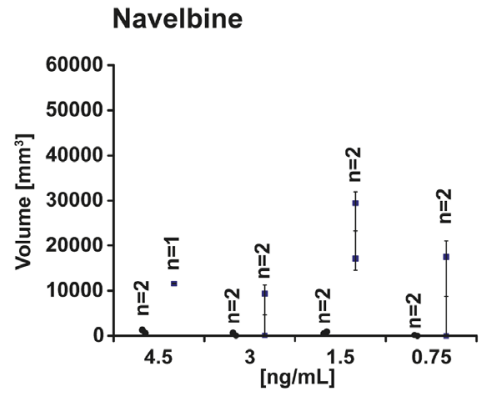

- MR volumetry 3 month p.i.

- MR volumetry 5 month p.i.

- $\left[{ }^{18}\right.$ F]FDG PET 5 month p.i.

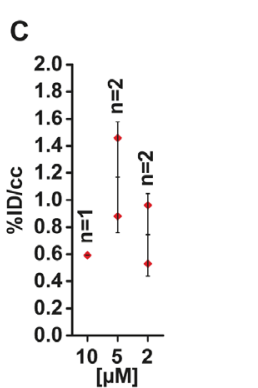

E

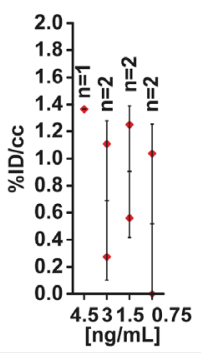

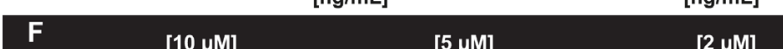

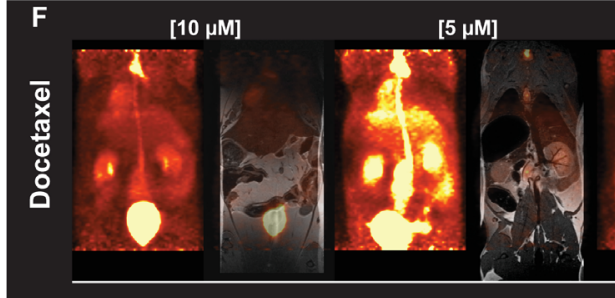

[2 $\mu \mathrm{M}]$
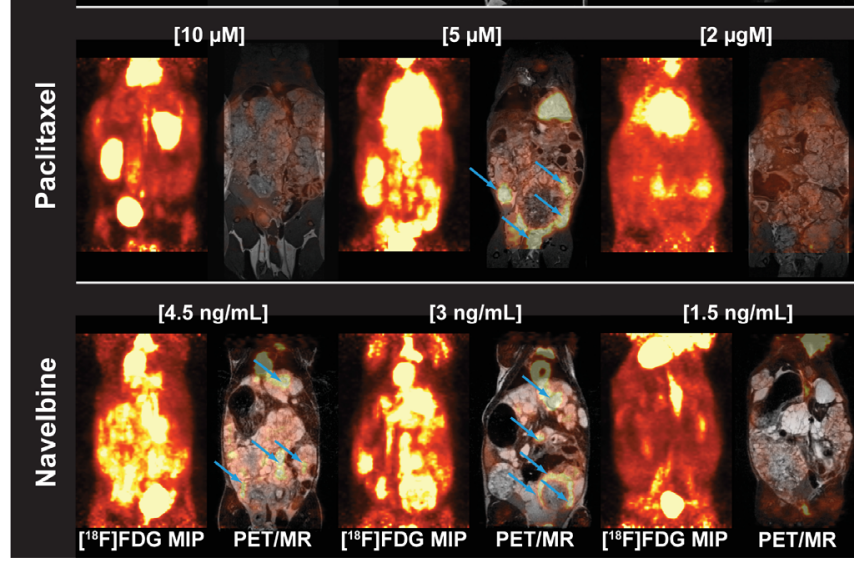

[0.75 ng/mL]

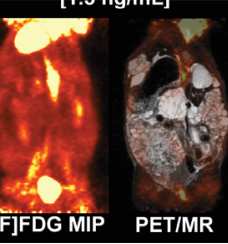

Figure 1: PET- and MR-imaging, and quantification of parasite growth, in docetaxel, paclitaxel and vorinostat (SAHA) exposed E.multilocularis metacestodes. In vivo quantification of parasite growth was performed at two time points in all tested animals. The in vivo grown volumes of docetaxel (A), paclitaxel (B) and navelbine (D) exposed E. multilocularis metacestodes is shown. At the second measurement time point $(\mathbf{F})$ and simultaneously to the MR acquisition all animals were PET imaged with $\left[{ }^{18} \mathrm{~F}\right] \mathrm{FDG}$. Quantification of the $\left[{ }^{18} \mathrm{~F}\right] \mathrm{FDG}$ uptake in parasite tissue is presented as percentage of the injected dose per cubic centimeter (\% $\left.\mathrm{ID} / \mathrm{cc}\right)$ and error bars represent one SD. Results are shown for docetaxel $(\mathbf{C})$, paclitaxel and navelbine (E) exposure. Coronal [ ${ }^{18}$ F]FDG maximum intensity projections (MIP) and fused PET/MR images from E. multilocularis metacestode infected gerbils are shown in the Figure 1F. Arrows indicate the positions of the $\left.{ }^{18} \mathrm{~F}\right] \mathrm{FDG}$ uptake in the metacestode tissue. (n.d., non detected). 
volumes detected by MRI at 2 months p.i. were 570 and $1290 \mathrm{~mm}^{3}(n=2), 51$ and $636 \mathrm{~mm}^{3}(n=2), 890$ and $468 \mathrm{~mm}^{3}(n=2)$ and 0 and $177 \mathrm{~mm}^{3}(n=2)$, respectively. At 5 months p.i., parasite tissue volumes of $11565 \mathrm{~mm}^{3}$ $(n=1), 78$ and $9337 \mathrm{~mm}^{3}(n=2), 17151$ and $29422 \mathrm{~mm}^{3}(n$ $=2)$ and 0 and $17496 \mathrm{~mm}^{3}(n=2)$ have grown in Meriones when the navelbine exposure concentrations were $4.5 \mathrm{ng} / \mathrm{ml}$, $3 \mathrm{ng} / \mathrm{ml} 1.5 \mathrm{ng} / \mathrm{ml}$ and $0.75 \mathrm{ng} / \mathrm{ml}$, respectively.

Animals inoculated with E. multilocularis metacestodes exposed to doxorubicin (Figure 2A and $2 \mathrm{H}$ ) showed comparable parasite growth as seen in the group treated with paclitaxel. At 2 months post inoculation, metacestodes exposed in vitro to doxorubicin at concentrations of $4.5 \mu \mathrm{g} / \mathrm{ml}, 3 \mu \mathrm{g} / \mathrm{ml}$ and $1.5 \mu \mathrm{g} / \mathrm{ml}$ developed in vivo in Meriones parasite tissue volumes of 7385 and $15138 \mathrm{~mm}^{3}(n=2), 2623$ and $967 \mathrm{~mm}^{3}(n=2)$ and 810 and $332 \mathrm{~mm}^{3}(n=2)$, respectively. At 5 months p.i., tissue volumes of $13426 \mathrm{~mm}^{3}(n=1), 39768$ and $2297 \mathrm{~mm}^{3}(n=2)$ and 11733 and $16953 \mathrm{~mm}^{3}(n=2)$ were present in the respective doxorubicin exposure groups.

In vivo growth of $E$. multilocularis metacestode was observed following in vitro exposure with vorinostat (SAHA) (Figure 2C and 2H). At 3 months post inoculation in Meriones, parasite tissues with volumes of 10879 and $412 \mathrm{~mm}^{3}(n=2), 0$ and $220 \mathrm{~mm}^{3}(n=1), 10887$ and $1470 \mathrm{~mm}^{3}(n=2)$ and 8204 and $521 \mathrm{~mm}^{3}(n=2)$ have developed from vorinostat (SAHA) $10 \mu \mathrm{g} / \mathrm{ml}, 7.5 \mu \mathrm{g} / \mathrm{ml}$, $5 \mu \mathrm{g} / \mathrm{ml}, 2.5 \mu \mathrm{g} / \mathrm{ml}$ exposed metacestodes, respectively. At 5 months post inoculation, MRI measurements could be conducted in Meriones with vorinostat (SAHA) $7.5 \mu \mathrm{g} / \mathrm{ml}$, $2 \mu \mathrm{g} / \mathrm{ml}$ and $1 \mu \mathrm{g} / \mathrm{ml}$ exposed metacestodes, and 755 and $0 \mathrm{~mm}^{3}(n=2), 20389$ and $44256 \mathrm{~mm}^{3}(n=2)$ and 24190 $\mathrm{mm}^{3}(n=1)$ of tissues were found, respectively.

The in vitro DMSO-exposed metacestode tissues which were transferred into Meriones were prominently enlarged in vivo at the first time point of measurement with $19264 \pm 38127 \mathrm{~mm}^{3}(n=5$; at 3 months post transfer) and on the second measurement 7606 and 5049 $\mathrm{mm}^{3}$ of parasite tissue was detected ( $n=2$; at 5 months post transfer) (Figure 2E and 2G control). Due to strong parasite growth in the DMSO control group, 3 animals had to be euthanized according to the animal welfare guidelines which resulted in a lower mean parasite burden at the second measurement time point.

\section{In vivo positron emission tomography (PET) and magnetic resonanz imaging (MRI) of Meriones unguiculatus infected with drug-exposed $\mathbf{E}$. multilocularis}

For the in vivo evaluation of the glucose metabolism, E. multilocularis infected and control Meriones were injected with the PET tracer $\left[{ }^{18} \mathrm{~F}\right] \mathrm{FDG}$ for glucose consumption, and PET/MRI were simultaneously performed at 5 months post infection in one set of experiments. When E. multilocularis metacestodes were exposed in vitro to docetaxel and these metacestodes then transferred into the peritoneum of Meriones, the PET quantification showed no uptake of $\left[{ }^{18} \mathrm{~F}\right]$ FDG in these animals, independent of the in vitro applied concentrations of docetaxel. An increased $\left[{ }^{18} \mathrm{~F}\right] \mathrm{FDG}$ tracer uptake of $0.6 \% \mathrm{ID} / \mathrm{cc}(n=1), 0.9$ and $1.5 \% \mathrm{ID} / \mathrm{cc}(n=2)$ and 0.5 and $1.0 \% \mathrm{ID} / \mathrm{cc}$ was seen in gerbils implanted with metacestode tissue exposed to paclitaxel at concentrations of $10 \mu \mathrm{g} / \mathrm{ml}, 5 \mu \mathrm{g} / \mathrm{ml}$ and $2 \mu \mathrm{g} / \mathrm{ml}$, respectively (Figure 1C). $1 \mathrm{~F}$ Meriones inoculated with navelbine-exposed $E$. multilocularis metacestodes, the $\left[{ }^{18} \mathrm{~F}\right] \mathrm{FDG}$ tracer uptake into parasite tissues was heterogeneous when compared to vorinostat and doxorubicin. Tracer uptake was $1.4 \% \mathrm{ID} / \mathrm{cc}$ $(n=1), 0.3$ and $1.1 \% \mathrm{ID} / \mathrm{cc}(n=2) ; 1.3$ and $0.6 \% \mathrm{ID} / \mathrm{cc}(n$ $=2)$ and 0 and $1.0 \% \mathrm{ID} / \mathrm{cc}(n=2)$ when metacestodes were exposed in vitro to navelbine at concentrations of $4.5 \mu \mathrm{g} / \mathrm{ml}$, $3 \mu \mathrm{g} / \mathrm{ml}, 1.5 \mu \mathrm{g} / \mathrm{ml}$ and $0.75 \mu \mathrm{g} / \mathrm{ml}$, respectively (Figure 1D).

The preceding in vitro exposure of metacestodes to doxorubicin led to a dose dependent uptake of $\left[{ }^{18} \mathrm{~F}\right]$ FDG in parasite tissue in Meriones with $0.7 \% \mathrm{ID} / \mathrm{cc}(n=$ $1), 0.6$ and $1.2 \% \mathrm{ID} / \mathrm{cc}(n=2)$, and 1.4 and $1.2 \% \mathrm{ID} / \mathrm{cc}$ $(n=2)$ when doxorubicin was applied at concentrations of $4.5 \mu \mathrm{g} / \mathrm{ml}, 3 \mu \mathrm{g} / \mathrm{ml}$ and $1.5 \mu \mathrm{g} / \mathrm{ml}$, respectively (Figure 2B). Similarly, in Meriones, a dose dependent uptake of the $\left[{ }^{18} \mathrm{~F}\right] \mathrm{FDG}$ tracer in E. multilocularis metacestode tissue was detected when the preceding in vitro exposure was with vorinostat (SAHA). Animals inoculated with E. multilocularis metacestodes treated with $10 \mu \mathrm{g} /$ $\mathrm{ml}$ vorinostat showed no uptake of $\left[{ }^{18} \mathrm{~F}\right] \mathrm{FDG}$ due to no parasite growth. Exposure with $7.5 \mu \mathrm{g} / \mathrm{ml}$ of vorinostat resulted in low $\left[{ }^{18} \mathrm{~F}\right]$ FDG uptake with 0 and $0.7 \% \mathrm{ID} /$ cc $(n=2)$; when metacestodes were exposed to $5 \mu \mathrm{g}$ / $\mathrm{ml}$ vorinostat then tracer uptake was 1.1 and $0.7 \% \mathrm{ID} / \mathrm{cc}$ $(n=2)$ and exposure with $2 \mu \mathrm{g} / \mathrm{ml}$ showed a tracer uptake of $1.1 \% \mathrm{ID} / \mathrm{cc}$ (Figure 2D). In Meriones transferred with DMSO-exposed E. multilocularis metacestodes (positive control) the uptake of $\left[{ }^{18} \mathrm{~F}\right] \mathrm{FDG}$ was at 1.3 and $1.2 \% \mathrm{ID} /$ cc $(n=2)$ (Figure 2F).

\section{The in vivo weights of $E$. multilocularis metacestodes after in vitro drug-exposure}

After the final PET scan at 5 months post infection, all Meriones were euthanized under deep anesthesia and parasite tissues were removed and weighted. $E$. multilocularis metacestode tissue masses of more than 10 $\mathrm{g}$ developed in Meriones injected with metacestodes which were previously exposed in vitro to doxorubicin (mean parasite tissue weight: $17.8 \mathrm{~g})$, navelbine $(12.0 \mathrm{~g})$, paclitaxel (11.6 g) or vorinostat (SAHA) (20.1 g), while in those animals which were injected with metacestodes previously exposed to docetaxel, the in vivo grown metacestodes weighted $0.2 \mathrm{~g}$ (Figure 3). In Figure 3 the weights of the in vivo grown metacestode tissues from the animal groups with selected drug concentrations were merged. 
- MR volumetry 3 month p.i. = MR volumetry 5 month p.i. $-\left[{ }^{18}\right.$ F]FDG PET 5 month $p . i$

A

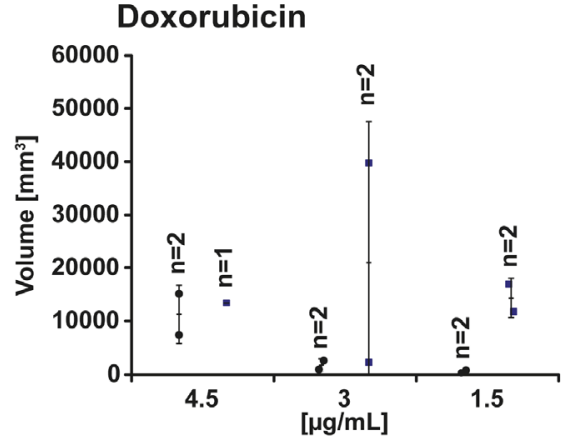

C

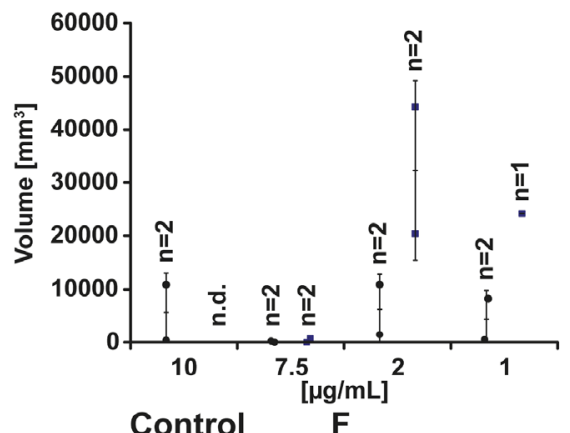

E
B

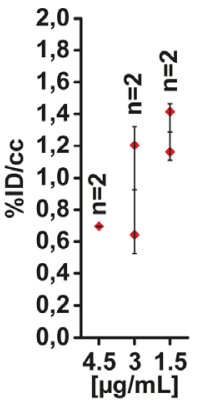

D

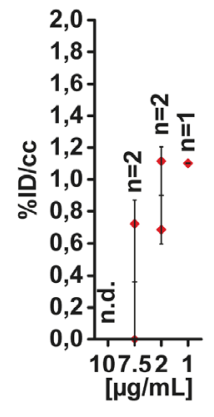

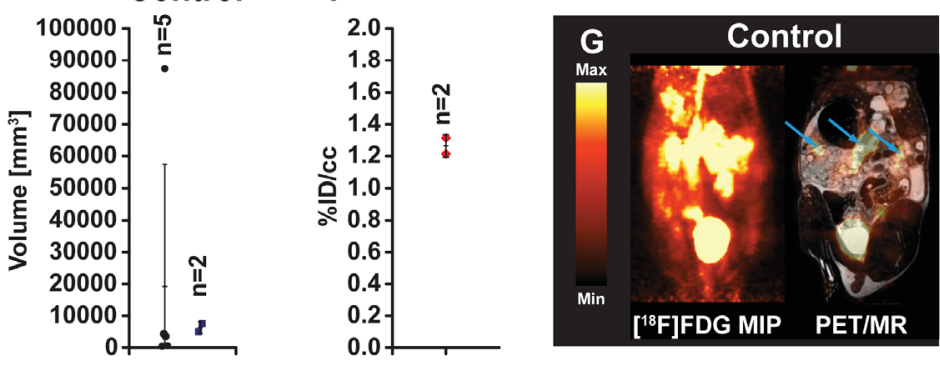

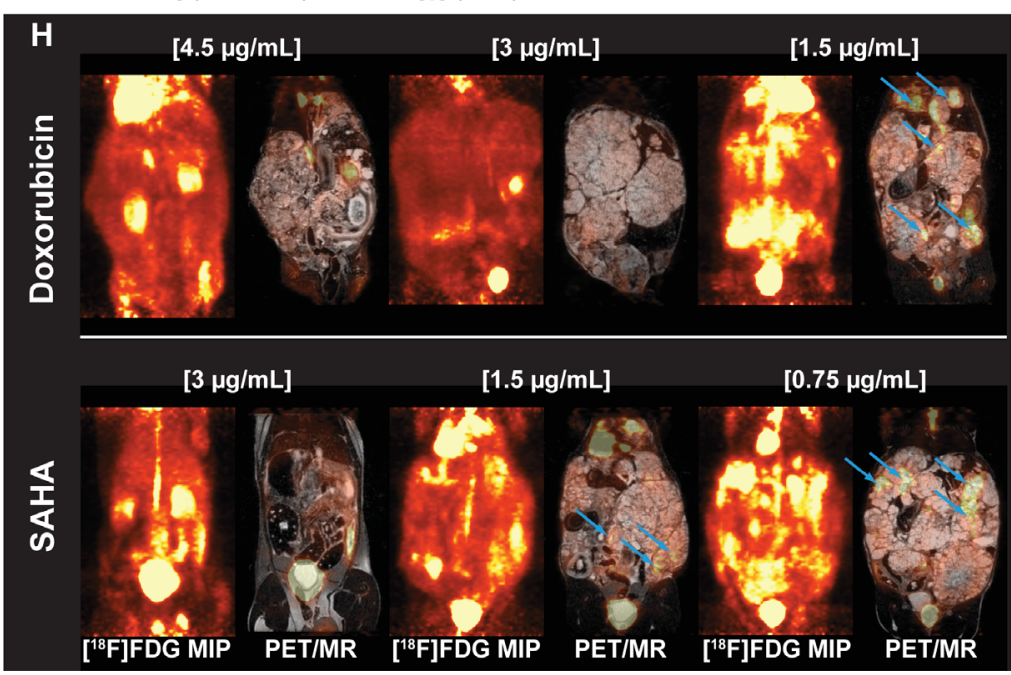

Figure 2: PET- and MR-imaging, and quantification of parasite volumes, in doxorubicin, vorinostat (SAHA) and DMSO (control) exposed $\boldsymbol{E}$. multilocularis metacestodes. In vivo quantification of parasite growth was performed at two time points in all tested animals. The parasite tissue volumes of doxorubicin (A), vorinostat (SAHA; C) and DMSO control (E) exposed E. multilocularis metacestodes is shown. At the second measurement time point and simultaneously to the MR acquisition all animals were PET imaged with $\left[{ }^{18} \mathrm{~F}\right] \mathrm{FDG}$. Quantification of the $\left[{ }^{18} \mathrm{~F}\right] \mathrm{FDG}$ uptake in parasite tissue is presented as percentage of the injected dose per cubic centimeter $(\% \mathrm{ID} / \mathrm{cc})$ and error bars represent one SD. Results are shown for doxorubicin $(\mathbf{B})$, vorinostat (SAHA; D) and DMSO control (F) treatment. Coronal $\left[{ }^{18} \mathrm{~F}\right] \mathrm{FDG}$ maximum intensity projections (MIP) and fused PET/MR images from E. multilocularis metacestode infected gerbils are depicted in the $(\mathbf{G}$ and $\mathbf{H})$. Arrows indicate the positions of the $\left[{ }^{18} \mathrm{~F}\right] \mathrm{FDG}$ uptake in the metacestode tissue. 


\section{The in vitro production "budding" of vesicles from E. multilocularis metacestode tissues after in vitro drug-exposure}

E. multilocularis metacestode tissues were exposed to cytostatic drugs or drug-free culture media (control) for 1 week and maintained in vitro for another week drugfree, then the drug-exposed metacestode tissue culture media were changed weekly and the produced ("budded") E. multilocularis vesicles (diameter 2 to $4 \mathrm{~mm}$ ) collected, counted and vesicle production scored (Figure 4). Metacestodes exposed to docetaxel did not produce vesicles until seven weeks post exposure, thereafter, few vesicles $(n=1-5)$ were budding off the metacestode tissue blocks, and then vesicle production increased slightly ( $n$ $=6-10$ ) from 10 weeks post exposure onwards. Already at 2-3 weeks post drug exposure, few vesicles $(n=1-5)$ were released from metacestode tissue blocks previously exposed to doxorubicin $(4.5,3$ and $1.5 \mu \mathrm{g} / \mathrm{ml})$, navelbine $(4.5,3,1.5$ and $0.75 \mu \mathrm{g} / \mathrm{ml})$, paclitaxel $(10 \mu \mathrm{M}, 5 \mu \mathrm{M}$ and $2 \mu \mathrm{M})$, vorinostat (SAHA) $(10,7.5,2$ and $1 \mu \mathrm{g} / \mathrm{ml})$ (Figure 5), and the vesicle budding remained at this level until 14 weeks post drug exposure; thereafter cultures were ended. In Figure 5 the respective vesicle productions at the selected drug concentrations are shown. The $E$. multilocularis metacestode tissue cultures exposed to the DMSO solvent control budded off vesicles shortly after exposure, the release of vesicles continued to increase for weeks and reached at 7 weeks post DMSO exposure a plateau level of production $(n=20-30)$ which continued such until 14 weeks post drug exposure (Figure 5).

\section{DICUSSION}

For AE patients treated with albendazole or mebendazole who experience severe side effects there are no alternative chemotherapeutics which reach beyond these classical benzimidazoles $[1,22]$. We have applied gene microarray profiling of E. multilocularis metacestodes which showed strongly expressed human cancer-related genes suggesting similarities between metacestode proliferation and malignancies. In this pre-clinical study we exposed in vitro E. multilocularis metacestodes in vitro to cytostatic drugs, then implanted those drug-exposed parasite tissues into Meriones unguiculatus (gerbils), and studied in vivo parasite growth and proliferation by MRI and PET. In vivo growth and proliferation of E. multilocularis metacestode tissues was inhibited by docetaxel, while with paclitaxel and navelbine the in vivo growth of metacestodes was suppressed only until 3 months post infection, thereafter, parasite tissues enlarged in both drug-exposure groups. The histone deacetylase inhibitor vorinostat (SAHA), and doxorubicin which mediates DNA damage and inhibits DNA synthesis,

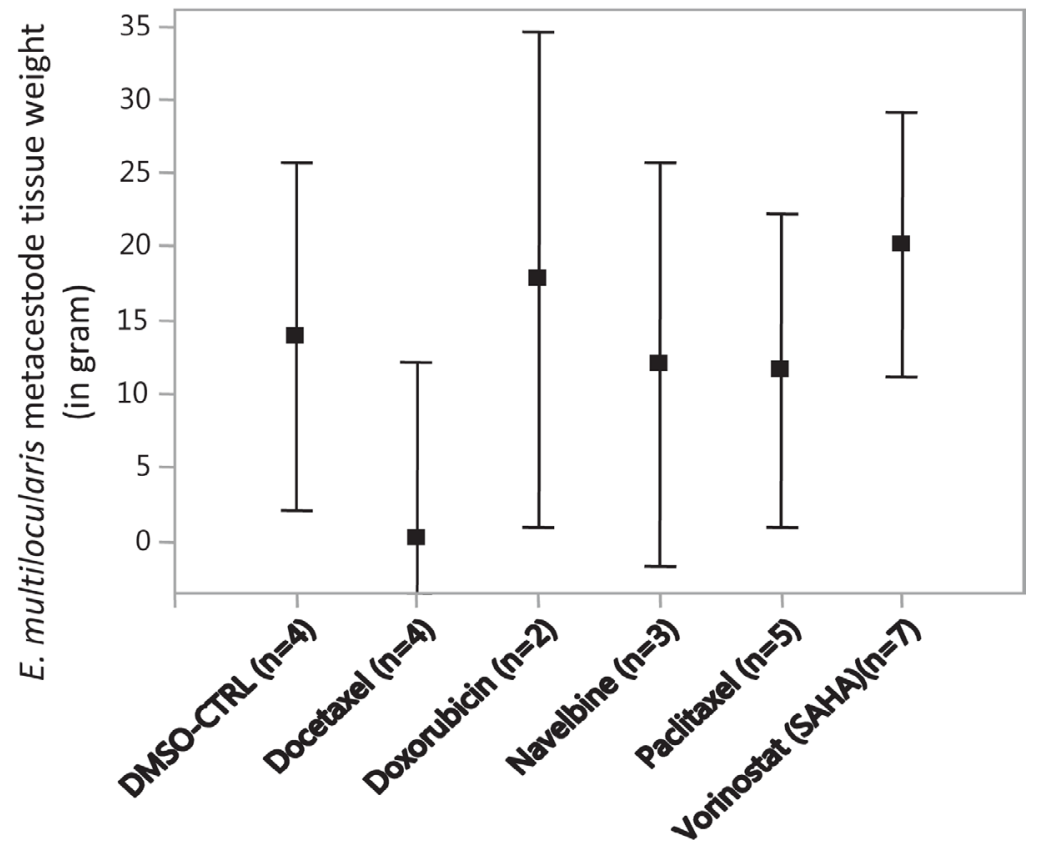

Figure 3: The weights of $\boldsymbol{E}$. multilocularis metacestodes tissues isolated from infected Meriones unguiculatus. Metacestodes were exposed in vitro to the cytostatic drugs docetaxel $(10 \mu \mathrm{M}, 5 \mu \mathrm{M}, 2 \mu \mathrm{M})$, doxorubicin $(4.5,3$ and $1.5 \mu \mathrm{g} / \mathrm{ml})$, navelbine $(4.5,3,1.5$ and $0.75 \mu \mathrm{g} / \mathrm{ml})$, paclitaxel $(10 \mu \mathrm{M}, 5 \mu \mathrm{M}$ and $2 \mu \mathrm{M})$, vorinostat (SAHA) $(10,7.5,2$ and $1 \mu \mathrm{g} / \mathrm{ml})$ and DMSO $(0.1 \%$, $0.05 \%$, solvent control, CTRL) at the indicated concentrations for 7 days, subsequently metacestodes rested in drug-free media for another 7 days, and then the drug-exposed metacestodes were injected into the peritoneum of $M$. unguiculatus. At 4 and 5 months post infection, the grown metacestode tissues were collected from M. unguiculatus and weighted. The drug concentration groups at which E. multilocularis metacestodes tissues were exposed to the cytostatic drugs are merged. The Figure shows the treatment groups, the mean metacestode tissue weights and the $95 \%$ confidence intervals. No significant differences in weights were observable between the treatment groups. 
were both not effective to inhibit E. multilocularis metacestode growth and proliferation, which is consistent with previous findings $[4,12]$.

New research approaches have been suggested which should explore new therapeutic molecules, exploit parasite gene signaling pathways, target $E$. multilocularis stem cells and dissect the metabolic metamorphosis of E. multilocularis metacestodes [23, 24]. There are several observations on antigenic similarities between $E$. granulosus and various tumor types [25, 26], and together with the finding on highly expressed tumor-related genes in metacestodes this suggested the evaluation of anticancer cytostatic drugs as treatment options for AE. The standard readout method for the assessment of drug efficacy is parasite weight determination subsequent to cyst resection from experimentally E. multilocularis infected mice, rats or gerbils. This method has pitfalls because necropsy can change the parasite mass due to cyst rupture and release of vesicle fluid, and the assessments of parasite viability based on parasite weights may not be exact because host connective tissue encapsulating the parasite makes a complete resection of the parasite mass difficult $[21,27]$. Previous works on in vitro drugexposure followed by in vivo growth monitoring, have exposed E. multilocularis metacestodes to mebendazole, then transferred these metacestodes into parasitepermissive gerbils Meriones unguiculatus where tissues did not grow [28], as determined by weight monitoring after dissection. Thus, the exposure of E. multilocularis metacestodes in vitro to mebendazole at concentrations above $0.1 \mu \mathrm{M}$ was parasitocidal [28], and similarly effective was treatment using mefloquine $(20 \mu \mathrm{M})$ against in vitro cultures of metacestodes but oral application of mefloquine to E. multilocularis-infected mice was ineffective, whereas oral albendazole application was highly effective [29]. Monitoring in vivo of the intraperitoneal parasite growth without sacrificing the animal is possible by MRI and ultrasound allowing the assessments of parasite tissue volumes and its in vivo growth [11, 21], and by using PET tracers the metabolic activity of parasite tissues can be monitored, e.g. after application of therapeutic drugs [20]. The application of non-invasive imaging techniques, notably delayed $\left[{ }^{18} \mathrm{~F}\right] \mathrm{FDG}$ PET, greatly facilitated the differentiation between active and inactive liver lesions in AE patients, and the results suggested that the combination of delayed $\left[{ }^{18} \mathrm{~F}\right] \mathrm{FDG}$ PET and specific serology may help to prevent recurrences observed after premature interruption of treatment [19]. Further, imaging methods, using disease specific tracers for immuno-PET, have significant potential as effective
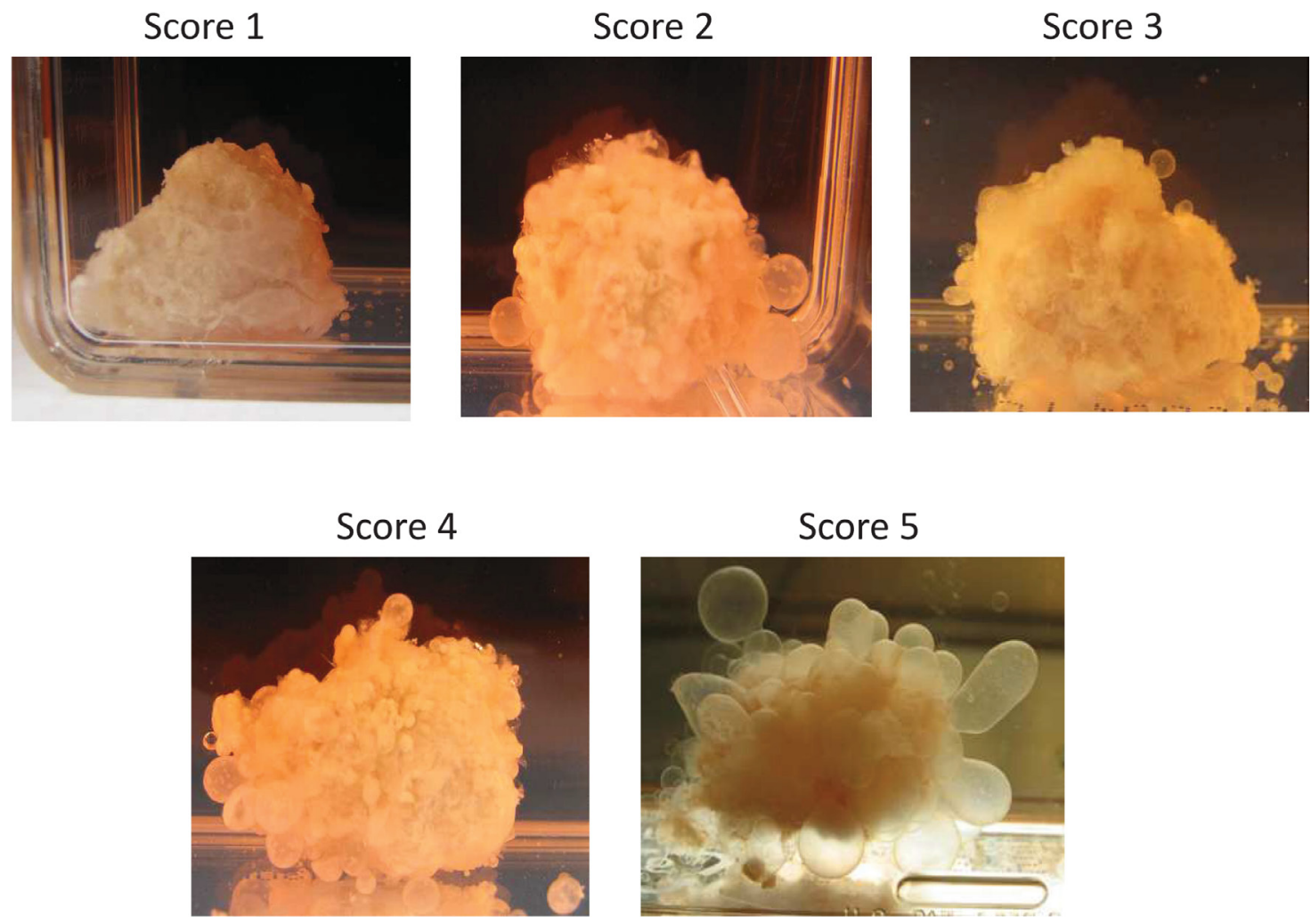

Figure 4. The in vitro "budding" of vesicles from E. multilocularis metacestode tissues after drug-exposure. The "budding" of $E$. multilocularis vesicles from in vitro cultured metacestodes tissue previously exposed in vitro to cytostatic drugs was evaluated during 14 weeks post drug exposure. The number of vesicles produced in culture was scored, i.e. Score $0=$ no vesicle, Score $1=$ very few vesicles (1-5), Score 2 few vesicles (6-10), Score $3=$ vesicles $(11-20)$, Score $4=$ vesicles $(21-30)$, Score $5=$ vesicles $(>31)$. The production scores 1-5 of E. multilocularis metacestodes tissues are shown. 

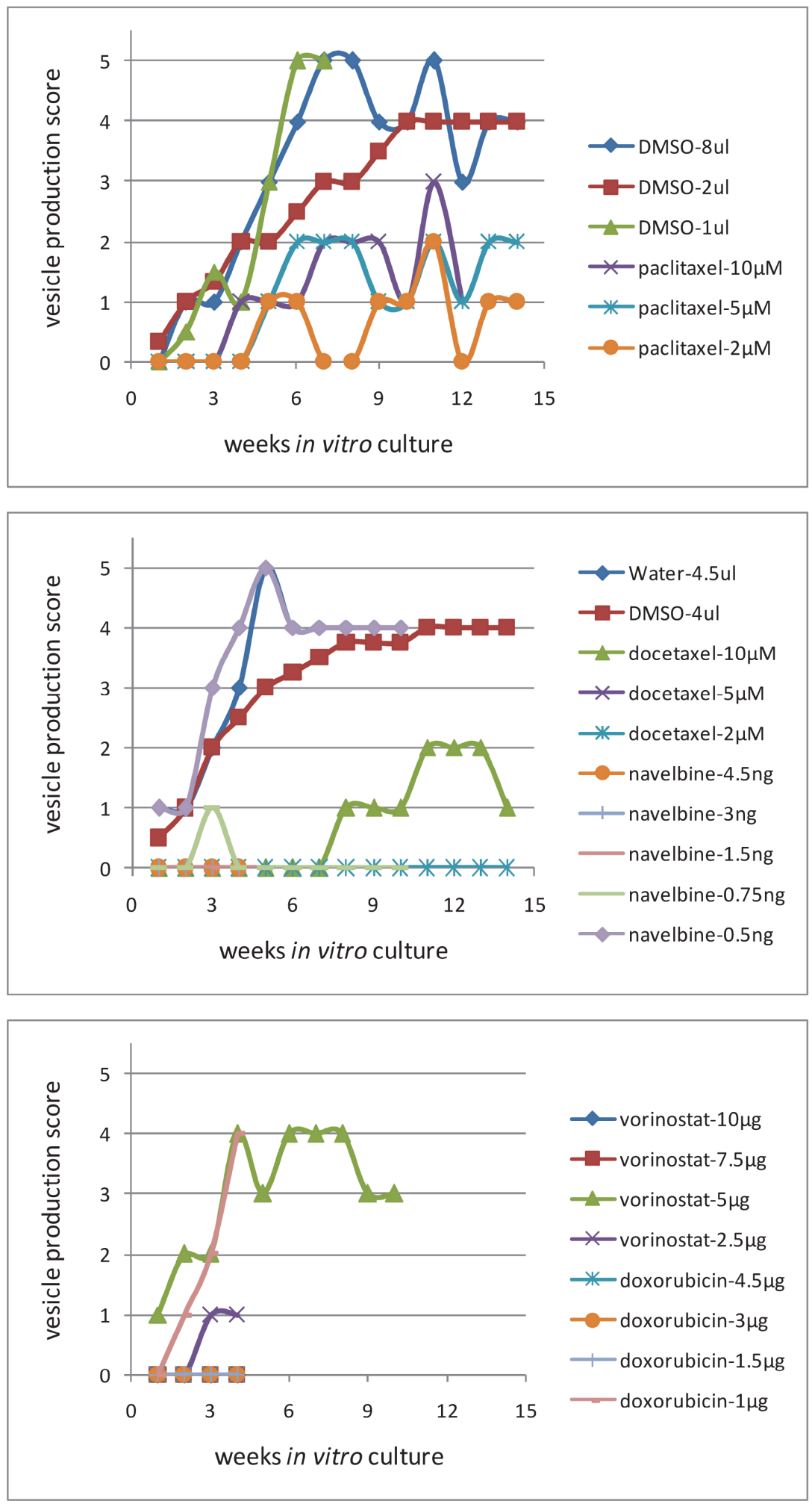

Figure 5: The in vitro production of vesicles from E. multilocularis metacestode tissues after in vitro drug-exposure. In vitro cultured E. multilocularis metacestode tissue blocks $\left(1 \mathrm{~cm}^{3}\right)$ were exposed to $10 \mu \mathrm{M}, 5 \mu \mathrm{M}, 2 \mu \mathrm{M}$ of docetaxel, to $4.5 \mu \mathrm{g} / \mathrm{ml}, 3 \mu \mathrm{g} / \mathrm{ml}$ and $1.5 \mu \mathrm{g} / \mathrm{ml}$ of doxorubicin, to $4.5 \mu \mathrm{g} / \mathrm{ml}, 3 \mu \mathrm{g} / \mathrm{ml}, 1.5 \mu \mathrm{g} / \mathrm{ml}$ and $0.75 \mu \mathrm{g} / \mathrm{ml}$ of navelbine, to $10 \mu \mathrm{M}, 5 \mu \mathrm{M}$ and $2 \mu \mathrm{M}$ paclitaxel, to $10 \mu \mathrm{g} / \mathrm{ml}$, $7.5 \mu \mathrm{g} / \mathrm{ml}, 2 \mu \mathrm{g} / \mathrm{ml}$ and $1 \mu \mathrm{g} / \mathrm{ml}$ of vorinostat (SAHA), and to DMSO (solvent control) at the indicated concentrations. The effects of these cytostatic compounds on the in vitro production by E. multilocularis vesicles was scored and studied for 14 weeks. The number of vesicles produced in culture was scored (Figure 5), i.e. Score $0=$ no vesicle, Score $1=$ very few vesicles $(1-5)$, Score $2=$ few vesicles $(6-10)$, Score $3=$ vesicles $(11-20)$, Score $4=$ vesicles $(21-30)$, Score $5=$ vesicles $(>31)$. 
tools to visualize infected tissues and cells, i.e. invasive pulmonary aspergillosis [18], and ligand-based targeting of specific cells or malignant tissues may help and guide surgeons to adequately resect infected while sparing critical tissues [30-32].

The taxanes paclitaxel, and docetaxel, a semisynthetic analogue of paclitaxel, are proven anti-cancer drugs and FDA-approved formulations of first line against advanced prostate cancer. Paclitaxel and docetaxel have a similar mechanism of action, they promote tubulin assembly and inhibit microtubule disassembly, stabilizing microtubule polymerization and thus blocking cells in the G2/M phase of the cell cycle thus triggering the signaling pathway that leads to apoptosis. Docetaxel is effective against tumor cells by inducing cell death, it inhibits the transcription of androgen receptors thus improving survival in metastatic hormone-resistant prostate cancer and also with tumors at earlier stages [33]. Navelbine is approved for the treatment of non-small cell lung cancer and metastatic breast cancer [34, 35]. Paclitaxel and docetaxel distribute into most tissues of mice and rats, including tumor tissue, but despite similarity in chemical structures their metabolic profile is distinct. Whereas paclitaxel metabolism is largely species dependent, docetaxel metabolism is similar across species, and for both taxanes, hepatobiliary excretion is the major pathway of elimination, and a major fraction of the dose is excreted in feces as parent drug or hydroxylated metabolites [36]. Albendazole remains the most common and effective treatment for AE, it targets tubulin but has its limitation, such as poor solubility and intestinal absorption and often there is no complete recovery after treatment. High dosage and lifelong uptake is required for albendazole in $\mathrm{AE}$ patients, which may lead to severe adverse effects [22]. Thus, less uptake time and high efficiency with paclitaxel and docetaxel may decreases the adverse effects and lead to potential treatments.

Recently, the anti-cancer drug bortezomib, a proteasome inhibitor developed for the chemotherapy of myeloma, displayed high anti-metacestodal activity, and Balb/c mice experimentally infected with E. multilocularis metacestodes presented with reduced parasite weights, but bortezomib treatment induced adverse effects such as diarrhea and neurological symptoms [12]. Previously, we found that navelbine suppressed in vivo E. multilocularis metacestode growth and proliferation [11], and the present results show that docetaxel visibly, and paclitaxel to a lesser extent, inhibited parasite growth. Similar results were reported by Pensel PE et al., who showed the paclitaxel can inhibit the survival of larval cell, protoscoleces and metacetodes of Echinococcus granulosus [9]. There are clinically relevant differences between docetaxel and paclitaxel, docetaxel is more cytotoxic than paclitaxel against a variety of murine and human tumor cell lines [37]. Both have been serving as important drugs for the treatment of various cancers, but drug resistance imposes limitations in their application since both have high affinity for multidrug-resistance proteins, in particular the drug efflux pump P-glycoprotein [38].

In conclusion, our observations advocate for drug combinations to be applied in experimental pre-clinical studies; which may provide essential information on their efficacy against E. multilocularis metacestodes, and ultimately this may translate into new treatment options against alveolar echinococcosis.

\section{MATERIAL AND METHODS}

\section{Animal model of alveolar echinococcosis}

All experiments were performed according to the German Animal Protection Law with permission from the Regierungspräsidium Tübingen as per guidelines from the European Health Law of the Federation of Laboratory Animal Science Associations (FELASA). Ten-week-old female gerbils (Meriones unguiculatus) were purchased from Charles River Laboratories (Sulzfeld, Germany) or bred in our animal facility. The animals were kept under standardized and sterile environmental conditions $\left(20^{\circ} \mathrm{C}\right.$ $\pm 1^{\circ} \mathrm{C}$ room temperature, $50 \% \pm 10 \%$ relative humidity, $12 \mathrm{~h}$ light-dark cycle) and received food and water ad lib.

E. multilocularis metacestode tissue was routinely maintained in gerbils using a modified method of serial implantation of parasite tissue as described previously $[39,11]$. The metacestode tissue was passed through a metal sieve with $1 \mathrm{~mm}^{2}$ width. M. unguiculatus (gerbils) were anesthetized with $2 \%$ isoflurane mixed with $100 \%$ oxygen and $0.5 \mathrm{ml}$ of the metacestode tissue cell suspension was injected into the peritoneum of each gerbil. After sufficient growth of the metacestode tissue, the gerbils were euthanized with $\mathrm{CO}_{2}$, and the parasite tissues were removed and used for in vitro culture assays and for in vivo transfer and maintenance of the E. multilocularis metacestodes.

\section{In vitro culture of $\mathbf{E}$. multilocularis metacestodes}

For in vitro cultivation of E. multilocularis, metacestode blocks were freshly and aseptically removed from the peritoneal cavity of experimentally infected gerbils (Meriones unguiculatus) [11, 39] and incubated with RPMI 1640 medium supplemented with 10\% FCS and $1 \%$ penicillin/streptomycin (Biochrom GmbH, Berlin, Germany) at $37^{\circ} \mathrm{C}$ and $5 \% \mathrm{CO}_{2}$. Medium was changed once a week for all cultures.

\section{Purification of $E$. multilocularis metacestodes total RNA, cDNA generation, labeling and oligonucleotide hybridization and microarray}

E. multilocularis metacestodes were cultured in vitro as described [11]. Metacestode tissue blocks which were not drug-exposed were snap frozen in liquid nitrogen, the deep frozen tissues were minced and homogenized with a 
tissue grinder, total RNA was purified by RNeasy Mini Kit (Qiagen, Hilden, Germany). The RNA was quantified with a Nanodrop UV spectrofluorometer and quality of RNA determined by Agilent Bioanalyzer 2100 (Agilent, CA, USA). Double-stranded cDNA was synthesized from 100 ng of total RNA and subsequently linearly amplified and biotinylated using the GeneChip ${ }^{\circledR}$ WT cDNA Synthesis and Amplification Kit (Affymetrix, Santa Clara, CA, USA) according to the manufacturer's instructions. Microarrays were analyzed with $15 \mu \mathrm{g}$ of labeled and fragmented cDNA hybridized to GeneChip ${ }^{\circledR}$ HumanGene 1.0 ST arrays (Affymetrix). After hybridization, the arrays were washed and stained in a Fluidics Station 450 (Affymetrix) with the recommended washing procedure. Biotinylated cDNA bound to target molecules was detected with streptavidincoupled phycoerythrin, biotinylated anti-streptavidin IgG antibodies and again streptavidin-coupled phycoerythrin according to the protocol. Arrays were scanned using the GCS3000 GeneChip scanner (Affymetrix) and AGCC 3.0 software. Scanned images were subjected to visual inspection to check for hybridization artifacts and proper grid alignment and analyzed with Expression Console 1.0 (Affymetrix) to generate report files for quality control. Normalization of raw data was performed by the Partek Software 6.6, applying an RMA (Robust Multichip Average) algorithm. For analysis, microarray hybridization data were converted to signal values using ArrayAssist 3.4 (Stratagene), and the signal strength of hybridization of the E. multilocularis cDNA samples to the human micro-array chip greater than 100 above background were selected. Two E. multilocularis metacestode samples, which were cultured as described above without having been exposed to anti-cancer drugs, were applied and the hybridization signals of both samples and their mean signal strength were aligned and are shown in Supplementary Table 1.

\section{Selection of cytostatic drugs}

Gene expression profiling in E. multilocularis metacestodes showed strongly expressed human cancerrelated genes which suggested similarities between $E$. multilocularis metacestode proliferation and cancer progression and tissue metastases. The signal strength of hybridization to human genes was prominent for member of the RAS oncogene family, the folate receptor, the eukaryotic translation elongation factor 1 alpha 1 , tubulin, aquaporin, calreticulin, and synuclein alpha (Supplementary Table 1). Based on these hybridization signals and specific gene expression FDA-approved formulations against advanced cancer were selected for the in vitro exposure of E. multilocularis metacestodes. Taxanes were selected for their capacity to stabilize microtubule polymerization thus blocking the cell cycle which leads to apoptosis. vorinostat (SAHA) was selected for inducing cell cycle arrest, doxorubicin for its capacity to mediate DNA damage and to inhibit DNA synthesis and proliferation, and both SAHA and doxorubicin may act in synergy to inhibit growth of tumor cells.

\section{Exposure of E. multilocularis to cytostatic drugs}

In vitro cultured E. multilocularis metacestode tissue blocks $\left(1 \mathrm{~cm}^{3}\right)$ were exposed to docetaxel, paclitaxel, navelbine, doxorubicin, or vorinostat in concentrations according to their recommended dosage for cancer treatment in humans. Metacestode tissues were exposed in vitro to $10 \mu \mathrm{M}, 5 \mu \mathrm{M}, 2 \mu \mathrm{M}$ of docetaxel (Sigma-Aldrich; \#01885-F), to 4.5 $\mu \mathrm{g} / \mathrm{ml}, 3 \mu \mathrm{g} / \mathrm{ml}$ and $1.5 \mu \mathrm{g} / \mathrm{ml}$ of doxorubicin (SigmaAldrich; \#44583), to $4.5 \mu \mathrm{g} / \mathrm{ml}, 3 \mu \mathrm{g} / \mathrm{ml}, 1.5 \mu \mathrm{g} / \mathrm{ml}$ and $0.75 \mu \mathrm{g} / \mathrm{ml}$ of navelbine (Pierre Fabre, Freiburg, Germany, $10 \mu \mathrm{g} / \mathrm{ml}$; UKT\#2698), to $10 \mu \mathrm{M}, 5 \mu \mathrm{M}$ and $2 \mu \mathrm{M}$ paclitaxel (Sigma-Aldrich; \#T7191), to $10 \mu \mathrm{g} / \mathrm{ml}$, $7.5 \mu \mathrm{g} / \mathrm{ml}, 2 \mu \mathrm{g} / \mathrm{ml}$ and $1 \mu \mathrm{g} / \mathrm{ml}$ of vorinostat (SAHA) (Sigma-Aldrich; SML0061) and to DMSO (SigmaAldrich; \#D8418) (0.1\%, 0.05\%; solvent control) at the indicated concentrations, and the effects of these cytostatic compounds on growth and proliferation of $E$. multilocularis metacestodes were evaluated in vitro and in vivo.

\section{E. multilocularis infection in vivo}

Metacestodes of E. multilocularis were cultured in vitro by established techniques [11] and the infection of $M$. unguiculatus was carried out according to the previous study [11]. In brief, metacestodes were exposed to cytostatic drugs or drug-free culture media (as above) for 1 week and then in vitro culture continued for another week in drug-free culture media. Thereafter, metacestode tissue blocks were split in half, one for further in vitro culture and monitoring of vesicle production and the other half was used to prepare the metacestode suspension for intra peritoneal injection (i.p.) in M. unguiculatus. The growth of drug-treated and untreated $E$. multilocularis metacestodes was monitored in vivo. All animals were examined for metacestode growth by in vivo magnetic resonance imaging (MRI) and tracer-guided positron emission tomography (PET). After the last PET scan at 5 months p.i., M. unguiculatus were autopsied, the Em-metacestode tissues removed and weighted. Most metacestode tissues were recovered from the peritoneal cavity either as singularly isolated masses or dissected from liver, kidney or gut tissues.

\section{Drug-exposure of in vitro cultured E. multilocularis metacestodes}

Drug-exposed metacestode tissue blocks were cultured in vitro as described previously [11]. One half of the drug exposed parasite tissue was incubated with RPMI 1640 medium supplemented with 10\% FCS and 
1\% penicillin/streptomycin (Biochrom GmbH, Berlin, Germany) at $37^{\circ} \mathrm{C}$ and $5 \% \mathrm{CO}_{2}$. The culture medium was changed once a week and E. multilocularis vesicles were collected from the cell culture and the number of produced vesicles (diameter 2 to $4 \mu \mathrm{M}$ ) counted. The number of vesicles produced in culture was scored (Figure 5), i.e. Score $0=$ no vesicle, Score $1=$ very few vesicles $(1-5)$, Score 2 = few vesicles (6-10), Score 3 = vesicles (11-20), Score $4=$ vesicles $(21-30)$, Score $5=$ vesicles $(>31)$.

\section{In vivo volumetric quantization of parasite growth}

For the volumetric evaluation of E. multilocularis metacestode growth in infected Meriones, in vivo MRI was performed using a 7T, $300 \mathrm{Mhz}$ small animal MR tomograph (Bruker Biospin MRI GmbH, Ettlingen, Germany) for the acquisition of anatomical information. The animals were anesthetized during the measurements with $1.5 \%$ isoflurane mixed with $100 \%$ oxygen under respiration monitoring. The images were acquired using a T2 fat saturated 3D sequence with a TE/TR of 90.51/1800.000 ms and data were analyzed using Inveon Research Workplace software (IRW, Siemens Preclinical Solutions, Knoxville, TN, USA). Parasite tissues were delineated from other organs based on the anatomical information obtained from the MR images and marked as regions of interest (ROIs) and quantified volumes are expressed as cubic millimeters.

\section{PET tracer production}

Fluorine-18 was produced as ${ }^{18} \mathrm{~F}$-fluoride at the PET trace cyclotron (General Electric Medical Systems, GEMS, Uppsala, Sweden) using the ${ }^{18} \mathrm{O}(\mathrm{p}, \mathrm{n}){ }^{18} \mathrm{~F}$ nuclear reaction, and $\left[{ }^{18} \mathrm{~F}\right] \mathrm{FDG}$ was synthesized as described [40].

\section{PET/MR imaging}

Simultaneous PET/MR imaging was performed with E. multilocularis infected gerbils 5 months p.i. In vivo bio-distribution of the PET tracer $\left[{ }^{18} \mathrm{~F}\right] \mathrm{FDG}$ was assessed using a small animal PET insert (Bruker Biospin $\mathrm{GmbH}$, Ettlingen, Germany) yielding a spatial resolution of approximately $1.3 \mathrm{~mm}$ in the reconstructed images [41]. All animals were shortly anaesthetized with isoflurane and $i . v$. injected with $10-12 \mathrm{MBq}$ of the tracer via a lateral tail vein. Static (10 min) PET scans were acquired after the injection of the tracer. During PET/MR imaging, the animals were anesthetized with $1.5 \%$ isoflurane mixed with $100 \%$ oxygen. Anesthesia was monitored by measuring the respiratory frequency, and the body temperature was kept at $37^{\circ} \mathrm{C}$ using a heating pad. PET data were acquired in listmode, histograms collected in one 10 min time frame and reconstructed using an iterative ordered subset expectation maximization (OSEM) algorithm. No attenuation correction was applied. MR imaging was performed as described above on a 7T, $300 \mathrm{Mhz}$ dedicated small animal MR tomograph obtaining anatomical information for parasite delineation. In addition to the T2 fat saturated $3 \mathrm{D}$ sequence, a T1 3D fast low angle shot (FLASH) sequence with a TE/TR of $6.000 / 30.000 \mathrm{~ms}$ was performed. PET images were normalized to each other, subsequently fused to the respective MR images and analyzed using IRW. ROIs were drawn around the respective tissue based on the anatomical information obtained from the MR images. Absolute quantification of the PET data is expressed as percentage of the injected dose per cubic centimeter $(\% \mathrm{ID} /$ cc). After the final PET scan, all animals were euthanized under deep anesthesia and parasite tissue was removed and weighted.

\section{Statistical analysis}

For the analysis of microarray data, significance was calculated using a $t$-test without corrections for multiple testing selecting all transcripts with a minimum change in expression level of 1.5-fold together with a $p$-value of less than 0.05 . The signal strength of hybridization of the E. multilocularis cDNA samples to the human microarray chip greater than 100 above background were selected.

\section{Abbreviations}

Alveolar echinococcosis (AE); benzimidazole (BMZ); Echinococcus multilocularis (Em); Food and Drug Administration (FDA); intra peritoneal (i.p.); Magnetic resonance imaging (MRI); maximum intensity projections (MIP); non detected (n.d.); nuclear magnetic resonance (NMR); positron emission tomography (PET); post infection (p.i.); 2-deoxy-2-[ $\left[{ }^{18} \mathrm{~F}\right]$-fluoro-D-glucose $\left(\left[{ }^{18} \mathrm{~F}\right] \mathrm{FDG}\right)$; percentage of the injected dose per cubic centimeter $(\% \mathrm{ID} / \mathrm{cc})$;

\section{Author contributions}

$\mathrm{XH}, \mathrm{SW}$ and PTS designed the experiments. $\mathrm{XH}$, SW, AMR, PV, WH and PTS performed experiments and analyzed data. XH, SW, AMR and PTS wrote the manuscript. $\mathrm{BG}$ and $\mathrm{CK}$ advised on experimental design and provided critical feedback. All authors reviewed the manuscript.

\section{CONFLICTS OF INTEREST}

The authors have no conflicts of interest to disclose.

\section{FUNDING}

This work was supported by the BadenWürttemberg Stiftung (Grant P-LS-AL2/06), the 
Bundesministerum für Bildung und Forschung (BMBF grant 01KA1008), the Deutsche Forschungsgemeinschaft (DFG grant WI3777/1-2) and the Werner Siemens Fundation.

\section{REFERENCES}

1. Kern P, Bardonnet K, Renner E, Auer H, Pawlowski Z, Ammann RW, Vuitton DA, Kern P. European Echinococcosis Registry. European echinococcosis registry: human alveolar echinococcosis, Europe, 1982-2000. Emerging Infectious Diseases. 2003; 9:343-349.

2. Lubinsky G, Lee CF, Baron RW. Attempts at chemotherapy of Echinococcus multilocularis infections in rodents. II. A study of some parasiticides and cytostatic agents. Canadian journal of zoology. 1971; 49:1301-1304.

3. Novak M. Efficacy of mitomycin C against alveolar Echinococcus. International journal of parasitology. 1990; 20:119-120.

4. Liance M, Nemati F, Bories C, Couvreur P. Experience with doxorubicin-bound polyisohexylcyanoacrylate nanoparticles on murine alveolar echinococcosis of the liver. Int $\mathrm{J}$ Parasitol. 1993; 23:427-9.

5. Naguleswaran A, Spicher M, Vonlaufen N, Ortega-Mora LM, Torgerson $\mathrm{P}$, Gottstein $\mathrm{B}$, Hemphill A. In vitro metacestodicidal activities of genistein and other isoflavones against Echinococcus multilocularis and Echinococcus granulosus. Antimicrobial Agents and Chemotherapy. 2006; 50:3770-3778.

6. Stadelmann B, Scholl S, Müller J, Hemphill A. Application of an in vitro drug screening assay based on the release of phosphoglucose isomerase to determine the structureactivity relationship of thiazolides against Echinococcus multilocularis metacestodes. Journal of Antimicrobial Chemotherapy. 2010; 65:512-519.

7. Hemer S, Brehm K. In vitro efficacy of the anticancer drug imatinib on Echinococcus multilocularis larvae. International journal of antimicrobial agents. 2012; 40:458-462. https://doi.org/10.1016/j.ijantimicag.2012.07.007.

8. Küster T, Kriegel N, Stadelmann B, Wang X, Dong Y, Vennerstrom JL, Keiser J, Hemphill A. Amino ozonides exhibit in vitro activity against Echinococcus multilocularis metacestodes. International journal of antimicrobial agents. 2014; 43:40-46.

9. Pensel PE, Albani C, Gamboa GU, Benoit JP, Elissondo MC. In vitro effect of 5-fluorouracil and paclitaxel on Echinococcus granulosus larvae and cells. Acta tropica. 2014; 140:1-9. https://doi.org/10.1016/j.actatropica.2014.07.013.

10. Spicher M, Naguleswaran A, Ortega-Mora LM, Müller J, Gottstein B, Hemphill A. In vitro and in vivo effects of 2-methoxyestradiol, either alone or combined with albendazole, against Echinococcus metacestodes. Experimental parasitology. 2008; 119:475-482. https://doi. org/10.1128/AAC.00553-08.
11. Hübner C, Wiehr S, Kocherscheidt L, Wehrl H, Pichler BJ, Schmid A, Kern P, Soboslay PT. Effects of in vitro exposure of Echinococcus multilocularis metacestodes to cytostatic drugs on in vivo growth and proliferation of the parasite. Parasitology research. 2010; 107:459-463.

12. Stadelmann B, Aeschbacher D, Huber C, Spiliotis M, Müller J, Hemphill A. Profound activity of the anti-cancer drug bortezomib against Echinococcus multilocularis metacestodes identifies the proteasome as a novel drug target for cestodes. PLoS neglected tropical diseases. 2014; 8:e3352.

13. McGrogan BT, Gilmartin B, Carney DN, McCann A. Taxanes, microtubules and chemoresistant breast cancer. Biochimica et biophysica acta. 2008; 1785:96-132.

14. Sato A. Vorinostat approved in Japan for treatment of cutaneous T-cell lymphomas: status and prospects. Onco targets and therapy. 2012; 5:67-76.

15. Cappetta D, Rossi F, Piegari E, Quaini F, Berrino L, Urbanek K, De Angelis A. Doxorubicin targets multiple players: A new view of an old problem. Pharmacological research. 2017; S1043-661830045-2. https://doi. org/10.1016/j.phrs.2017.03.016.

16. Judenhofer MS, Wehrl HF, Newport DF, Catana C, Siegel SB, Becker M, Thielscher A, Kneilling M, Lichy MP, Eichner M, Klingel K, Reischl G, Widmaier S, et al. Simultaneous PET-MRI: a new approach for functional and morphological imaging. Nat Med. 2008; 14:459-465. https://doi.org/10.1038/nm1700.

17. Honndorf VS, Wiehr S, Rolle AM, Schmitt J, Kreft L, Quintanilla-Martinez L, Kohlhofer U, Reischl G, Maurer A, Boldt K, Schwarz M, Schmidt H, Pichler BJ. Preclinical evaluation of the anti-tumor effects of the natural isoflavone genistein in two xenograft mouse models monitored by [18F]FDG, [18F]FLT, and [64Cu]NODAGA-cetuximab small animal PET. Oncotarget. 2016; 7:28247-28261. https://doi.org/10.18632/oncotarget.8625.

18. Rolle AM, Hasenberg M, Thornton CR, Solouk-Saran D, Männ L, Weski J, Maurer A, Fischer E, Spycher PR, Schibli R, Boschetti F, Stegemann-Koniszewski S, Bruder D, et al. ImmunoPET/MR imaging allows specific detection of Aspergillus fumigatus lung infection in vivo. Proceedings of the national academy of science USA. 2016; 113: E1026-1033. https://doi.org/10.1073/pnas.1518836113.

19. Caoduro C, Porot C, Vuitton DA, Bresson-Hadni S, Grenouillet F, Richou C, Boulahdour H, Blagosklonov O. The role of delayed 18F-FDG PET imaging in the follow-up of patients with alveolar echinococcosis. Journal of nuclear medicine. 2013; 54:358-363. https://doi.org/10.2967/jnumed.112.109942.

20. Rolle AM, Soboslay PT, Reischl G, Hoffmann WH, Pichler BJ, Wiehr S. Evaluation of the Metabolic Activity of Echinococcus multilocularis in Rodents Using Positron Emission Tomography Tracers. Molecular imaging and biology. 2015; 17:512-520. https://doi.org/10.1007/ s11307-014-0815-3. 
21. Gorgas D, Marreros N, Rufener R, Hemphill A, LundströmStadelmann B. To see or not to see: non-invasive imaging for improved readout of drug treatment trials in the murine model of secondary alveolar echinococcosis. Parasitology. 2017; 8:1-8. https://doi.org/10.1017/S0031182017000051.

22. Budke CM, Casulli A, Kern P, Vuitton DA. Cystic and alveolar echinococcosis: Successes and continuing challenges. PLoS neglected tropical diseases. 2017; 11:e0005477. https://doi.org/10.1371/journal.pntd.0005477.

23. Brehm K, Koziol U. Echinococcus-Host Interactions at Cellular and Molecular Levels. Adv Parasitology. 2017; 95:147-212. https://doi.org/10.1016/bs.apar.2016.09.001

24. Hemphill A, Spicher M, Stadelmann B, Mueller J, Naguleswaran A, Gottstein B, Walker M. Innovative chemotherapeutical treatment options for alveolar and cystic echinococcosis. Parasitology. 2007; 134:1657-70.

25. van Knapen F. Echinococcus granulosus infection and malignancy. British Medical Journal. 1980; vol. 281, no. 6234, pp. 195-196.

26. Alvarez-Errico D, Medeiros A, Miguez M, Casaravilla C, Malgor R, Carmona C, Nieto A, Osinaga E. O-glycosylation in Echinococcus granulosus: identification and characterization of the carcinoma-associated Tn antigen. Experimental Parasitology. 2001; 98:100-109.

27. Hemphill A, Stadelmann B, Rufener R, Spiliotis M, Boubaker G, Müller J, Müller N, Gorgas D, Gottstein B. Treatment of echinococcosis: albendazole and mebendazole -what else? Parasite. 2014; 21:70. https://doi.org/10.1051/ parasite/2014073.

28. Jura H, Bader A, Frosch M. In vitro activities of benzimidazoles against Echinococcus multilocularis metacestodes. Antimicrobial agents and chemotherapy. 1998; 42:1052-1056.

29. Küster T, Stadelmann B, Hermann C, Scholl S, Keiser J, Hemphill A. In vitro and in vivo efficacies of mefloquinebased treatment against alveolar echinococcosis. Antimicrobial agents chemotherapy. 2011; 55:713-721. https://doi.org/10.1128/AAC.01392-10.

30. Harmsen S, Teraphongphom N, Tweedle MF, Basilion JP, Rosenthal EL. Optical Surgical Navigation for Precision in Tumor Resections. Molecular imaging and biology. 2017; 19:357-362. https://doi.org/10.1007/s11307-017-1054-1.
31. Claudon M, Bessieres M, Regent D, Rodde A, Bazin C, Gerard A, Bresler L. Alveolar echinococcosis of the liver: MR findings. Journal of computer assisted tomography. 1990; 14:608-14.

32. Duewell S, Marincek B, von Schulthess GK, Ammann R. [MRT and CT in alveolar echinococcosis of the liver]. Rofo. 1990; 152:441-445.

33. Ojima I, Lichtenthal B, Lee S, Wang C, Wang X. Taxane anticancer agents: a patent perspective. Expert opinion on therapeutic patents. 2016; 26:1-20. https://doi.org/10.1517 /13543776.2016.1111872.

34. Grossi F, Kubota K, Cappuzzo F, de Marinis F, Gridelli C, Aita M, Douillard JY. Future scenarios for the treatment of advanced non-small cell lung cancer: focus on taxanecontaining regimens. Oncologist. 2010; 15:1102-1112. https://doi.org/10.1634/theoncologist.2010-0322.

35. Xu YC, Wang HX, Tang L, Ma Y, Zhang FC. A systematic review of vinorelbine for the treatment of breast cancer. Breast journal. 2013; 19:180-188. https://doi.org/10.1111/tbj.12071.

36. Sparreboom A, van Tellingen O, Nooijen WJ, Beijnen JH. Preclinical pharmacokinetics of paclitaxel and docetaxel. Anticancer Drugs. 1998; 9:1-17.

37. Crown J. Docetaxel: overview of an active drug for breast cancer. Oncologist. 2001; 6:1-4.

38. Goldstein LJ. MDR1 gene expression in solid tumors. European journal of cancer. 1996; 32A:1039-1050.

39. Hemphill A, Gottstein B. Immunology and morphology studies on the proliferation of in vitro cultivated Echinococcus multilocularis metacestodes. Parasitology research. 1995; 81:605-614.

40. Hamacher K, Coenen HH, Stocklin G. Efficient stereospecific synthesis of no-carrier-added 2-[18F]-fluoro2-deoxy-D-glucose using aminopolyether supported nucleophilic substitution. Journal of nuclear medicine 1986; 27:235-238.

41. Wehrl HF, Hossain M, Lankes K, Liu CC, Bezrukov I, Martirosian P, Schick F, Reischl G, Pichler BJ. Simultaneous PET-MRI reveals brain function in activated and resting state on metabolic, hemodynamic and multiple temporal scales. Nature Medicine. 2013; 19:1184-1189. 